\title{
Litiasis urinaria secundaria a cuerpo extraño
}

\author{
Ramírez Sevilla C, Gómez Lanza E, Tremps Velázquez E, Morote Robles J.
}

Servicio de Urología. Hospital Universitario Vall d'Hebrón. Barcelona.

Actas Urol Esp. 2007;31(5):569

$\mathrm{P}$ aciente mujer de 81 años de edad con antecedentes patológicos de diabetes mellitus tipo I, hipertensión arterial y demencia senil severa, que acude a nuestro centro remitida de su residencia por presentar infecciones urinarias de repetición y pielonefritis aguda con urocultivo positivo a $\mathrm{P}$ aeruginosa multirresistente. A la exploración física se encuentra consciente, desorientada, febril y asintomática. $\mathrm{RX}$ abdomen: catéter ureteral doble jota derecho de 15 meses de evolución, gran litiasis vesical en el extremo distal del catéter, litiasis múltiple en el extremo proximal y litiasis ureteral de unos $2 \mathrm{~cm}$ a nivel de L3-L4. Con estudio preoperatorio correcto se decide tratamiento quirúrgico (Figs. 1, 2 y 3).

Correspondencia autor: Dr. C. Ramírez Sevilla Servicio de Urología. Hospital Universitario Vall d'Hebrón. Passeig de la Vall d'Hebrón, 119-129 - 08035 Barcelona Tel.: 932746000

E-mail autor: cjrs70@yahoo.com

Información artículo: Nota clínica

Trabajo recibido: marzo 2006

Trabajo aceptado: abril 2006

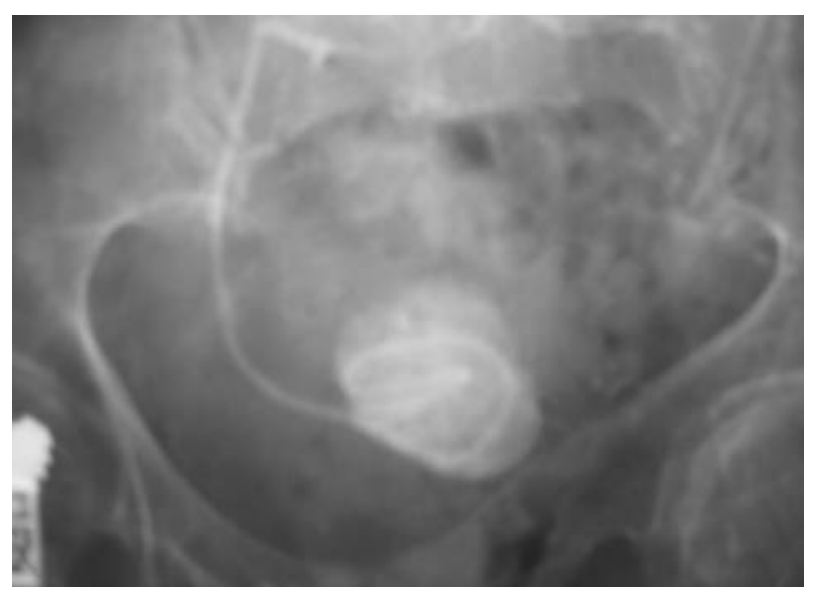

FIGURA 1

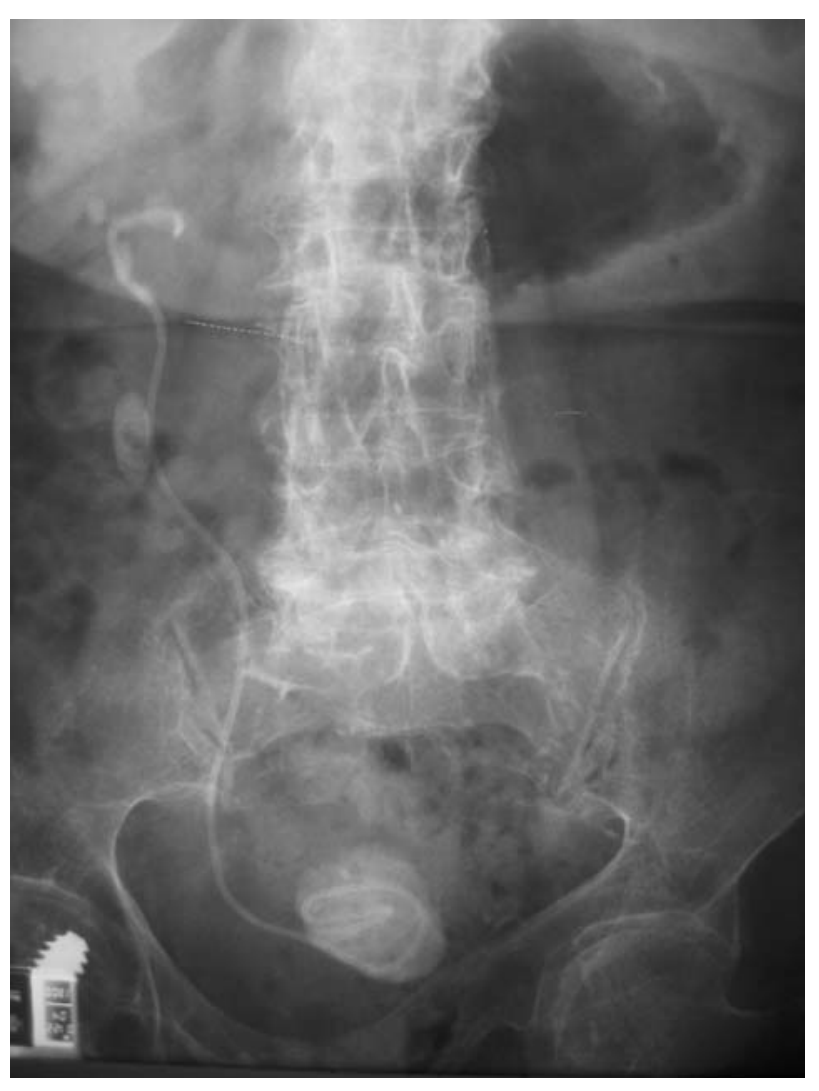

FIGURA 2

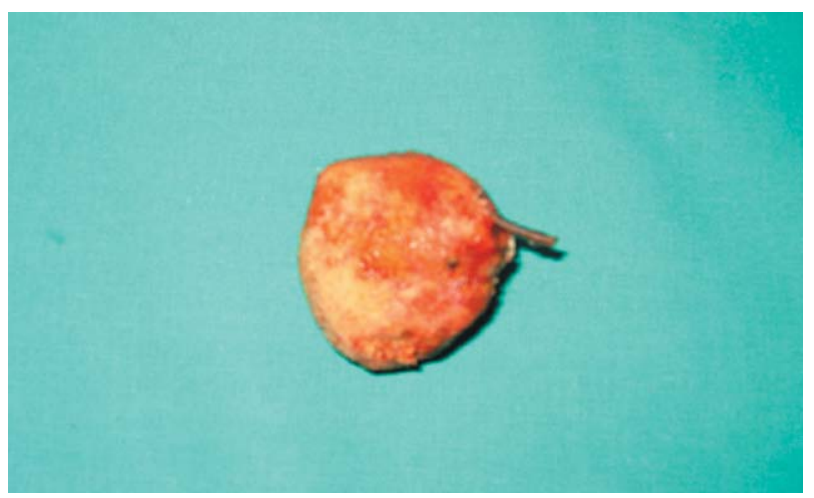

FIGURA 3 